\title{
not approved]
}

\author{
Andrianto Andrianto (D1) Ni Putu Anggun Laksmi (i1), Rio Herdyanto² \\ ${ }^{1}$ Department of Cardiology and Vascular Medicine, Universitas Airlangga - Dr. Soetomo Hospital, Surabaya, East Java, 60286, \\ Indonesia \\ 2Department of Cardiology and Vascular Medicine, Dr. R. Sosodoro Djatikoesomo Hospital, Bojonegoro, East Java, 62119, Indonesia
}

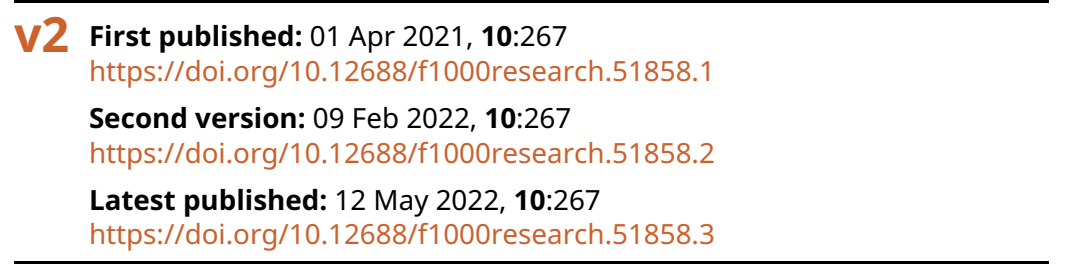

\section{Abstract}

Myocardial infarction (MI) is frequently complicated

by the worsening of renal function. Undergoing primary percutaneous coronary intervention (PCI) becomes crucial to a patient with STsegment elevation myocardial infarction (STEMI). With appropriate management of MI, acute-on-chronic kidney disease (ACKD) requiring dialysis post-MI remains an important clinical predictor of elevated inhospital mortality among patients with MI.

In this study, we reported an octogenarian patient suffering from STEMI with ACKD and total atrioventricular block (TAVB). She underwent insertion of a temporary pacemaker and primary PCI. Renal function was improved after dialysis by decreasing the amount of serum creatinine from 8.1 $\mathrm{mg} / \mathrm{dL}$ at admission to $1.05 \mathrm{mg} / \mathrm{dL}$ after primary PCI and dialysis. Primary PCI should still be considered for patients with acute MI, even though these patients have kidney disease, to save the heart muscle and even indirectly improve the kidney function itself.

\section{Keywords}

primary PCI, dialysis, acute myocardial infarction, STEMI, acute-onchronic kidney disease

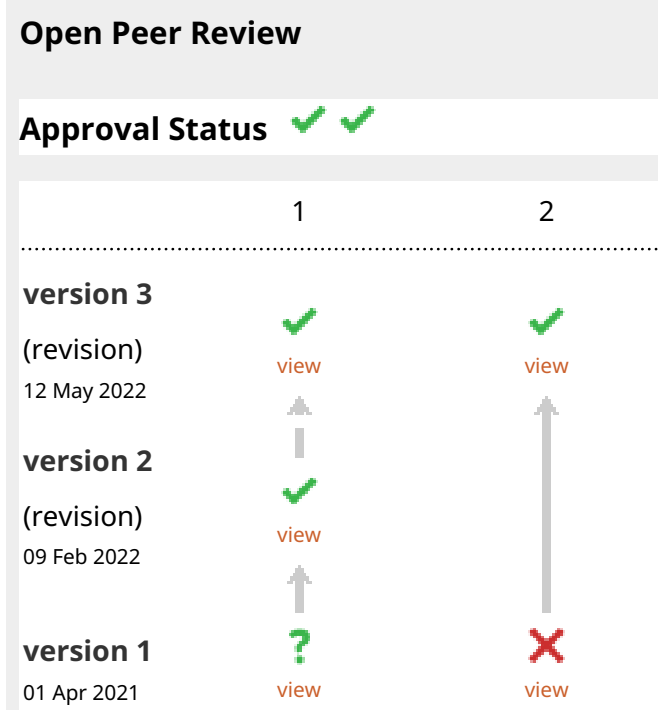

1. Mohammad Ullah Firoze (iD), Dhaka Medical College, Dhaka, Bangladesh

2. Dike B Ojji iD, University of Abuja, Abuja, Nigeria

Any reports and responses or comments on the article can be found at the end of the article. 
Corresponding author: Ni Putu Anggun Laksmi (anggunputu@gmail.com)

Author roles: Andrianto A: Conceptualization, Data Curation, Project Administration, Resources, Supervision, Validation, Visualization, Writing - Review \& Editing; Laksmi NPA: Formal Analysis, Investigation, Methodology, Software, Writing - Original Draft Preparation, Writing - Review \& Editing; Herdyanto R: Data Curation, Investigation, Resources, Writing - Review \& Editing

Competing interests: No competing interests were disclosed.

Grant information: Indonesian Endowment Fund for Education (Lembaga Pengelola Dana Pendidikan)

The funders had no role in study design, data collection and analysis, decision to publish, or preparation of the manuscript.

Copyright: ( $) 2022$ Andrianto A et al. This is an open access article distributed under the terms of the Creative Commons Attribution License, which permits unrestricted use, distribution, and reproduction in any medium, provided the original work is properly cited.

How to cite this article: Andrianto A, Laksmi NPA and Herdyanto R. Case Report: Successful primary percutaneous coronary intervention in octogenarian with acute-on-chronic kidney disease and total atrioventricular block after acute myocardial infarction [version 2; peer review: 1 approved, 1 not approved] F1000Research 2022, 10:267

https://doi.org/10.12688/f1000research.51858.2

First published: 01 Apr 2021, 10:267 https://doi.org/10.12688/f1000research.51858.1 


\section{REVISED Amendments from Version 1}

We attached the ECG result during inferior STEMI with TAVB in this patient (Figure 1). We also attached the picture of coronary angiography that clearly show total occlusion of right coronary artery (Figure 2a). We also included the management of TAVB in ACS in the discussion.

\section{Any further responses from the reviewers can be found at the end of the article}

\section{Introduction}

The incidence of acute-on-chronic kidney disease (ACKD) varies among patients with ST-segment elevation myocardial infarction (STEMI), ranging from 5\% to 30\%. The structural and functional changes in the kidneys leading to chronic kidney disease (CKD) is most likely to be caused by different pathological mechanisms, including renal hypoperfusion, ischemia, and nephrotoxicity. Despite the proper treatment of myocardial infarction, ACKD still leads to a higher risk of morbidity and mortality, particularly when dialysis is required.

Octogenarian patients were rarely included in clinical investigations. Patients of advanced age possess the dilemma of revascularization therapy. Many clinicians fear that the risk-benefit ratio of doing the primary PCI is not worth it on elderly patients. ${ }^{2}$ Fox et al. states the risk of death in patient with ACS is increasing with age, but elderly patients may get an equal or greater benefit from primary PCI. ${ }^{3}$

\section{Case presentation}

An 80-year-old Asian woman, with no history of smoking and unremarkable medical history, was referred to the emergency room department with a complaint of typical chest pain. The pain began four hours before hospitalization. It further radiated to the back and was accompanied by cold sweats. In this regard, the patient had a history of hypertension. Blood pressure was $116 / 53 \mathrm{mmHg}$, pulse rate was $39 \times / \mathrm{min}$, respiration rate was $23 \times / \mathrm{min}$, body temperature was $36.7^{\circ} \mathrm{C}$, and oxygen saturation was $96 \%$ with $\mathrm{O}_{2}$ nasal cannula $3 \mathrm{l} / \mathrm{min}$. Her extremities were warm, with vesicular pulmonary arteries and with no crackles or wheezing.

The electrocardiogram (ECG) of the patient showed TAVB with a junctional escape rhythm of 46 times per minute and inferior STEMI (Figure 1). The laboratory results of the initial visit were within normal limits, except that the blood urea nitrogen $(\mathrm{BUN}) 138 \mathrm{mg} / \mathrm{dL}$ (normal range: $8-23 \mathrm{mg} / \mathrm{dL}$ ), creatinine serum $8.1 \mathrm{mg} / \mathrm{dL}$ (normal range: 0.6 $1.3 \mathrm{mg} / \mathrm{dL}$ ), haemoglobin $(\mathrm{Hb}) 8.6 \mathrm{~g} / \mathrm{dl}$ (normal range: $11.5-16.5 \mathrm{~g} / \mathrm{dl}$ ) and troponin I increased to $30.6 \mathrm{ng} / \mathrm{mL}$ (normal range: $\leq 0.04 \mathrm{ng} / \mathrm{mL}$ ).

From these data, we provided this patient with a diagnosis of inferior STEMI with total AV block and ACKD. She was administered with aspilet $300 \mathrm{mg}$ and clopidogrel $75 \mathrm{mg}$ per oral. Subsequently, a temporary pacemaker (TPM) was installed using local anesthesia with the heart rate at $70 \times / \mathrm{min}$, the sensitivity at $3 \mathrm{mV}$ and the output at $3 \mathrm{~V}$, and diagnostic coronary angiography (DCA) was performed.

According to the DCA, the total occlusion was at the proximal right coronary artery (RCA) (Figure 2). There was insignificant stenosis in the proximal-mid left anterior descending artery. Besides, there were no stenosis on the left circumflex artery and the left main coronary artery. Primary PCI at the RCA was conducted using drug eluting stent (DES) promus and then thrombolysis in myocardial infarction (TIMI) grade 3 flow was shown at the RCA (Figure 3). Electrocardiography was also conducted after the installation of the pacemaker (Figure 4).

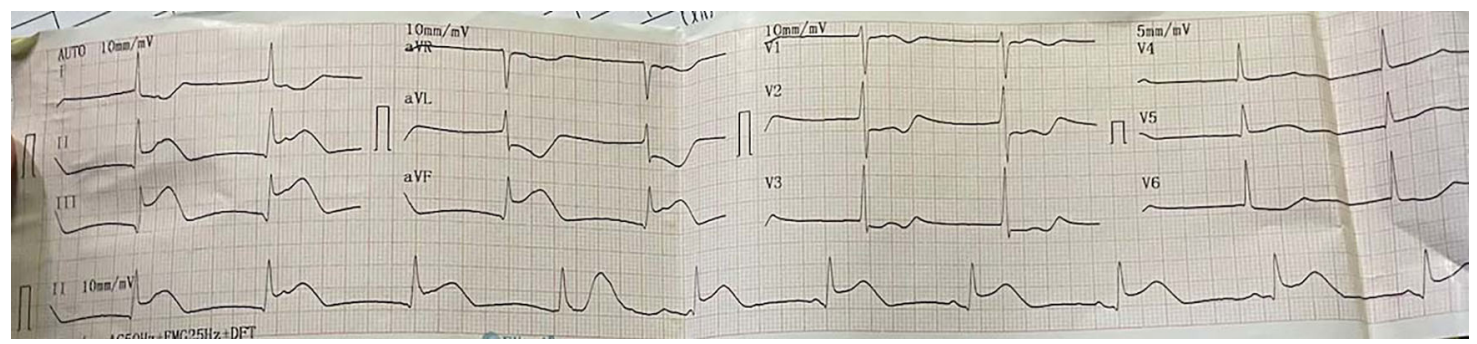

Figure 1. Initial presentation of electrocardiogram with inferior ST-elevation myocardial infarction. 


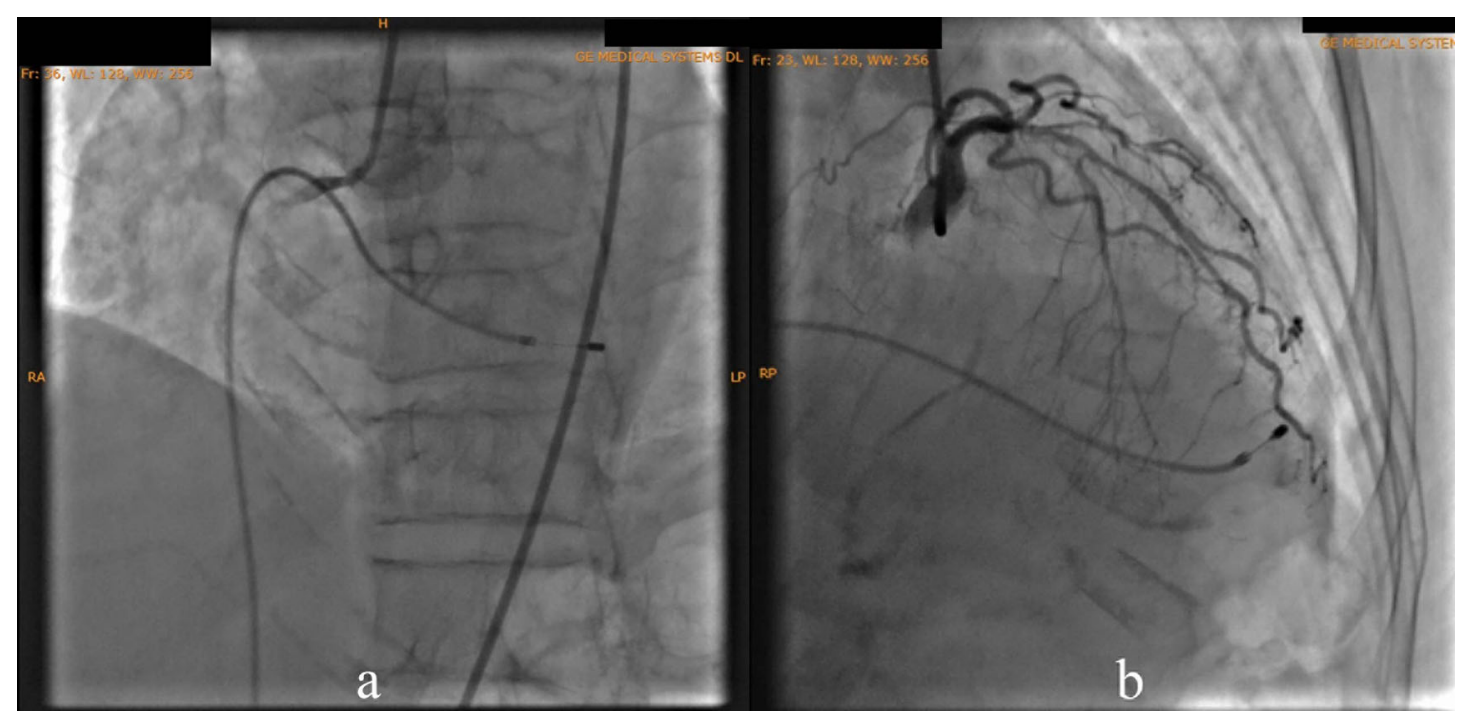

Figure 2. Total occlusion in proximal right coronary artery and $30 \%$ in proximal-mid left anterior descending artery.

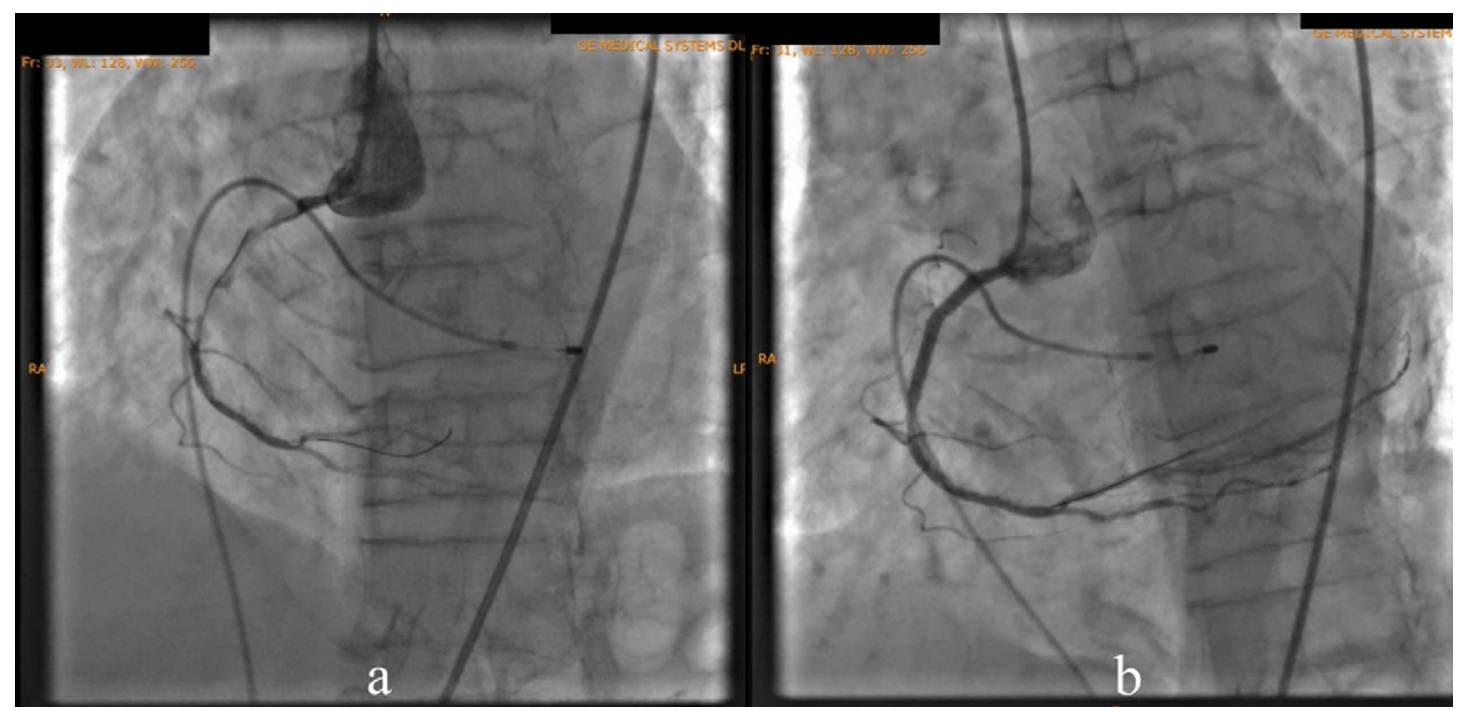

Figure 3. Primary percutaneous coronary intervention at proximal-mid right coronary artery with thrombolysis in myocardial infarction flow 3.

The patient was given therapy with dual antiplatelet aspirin $1 \times 100 \mathrm{mg}$ per oral and clopidogrel $1 \times 75 \mathrm{mg}$ per oral, atorvastatin $1 \times 20 \mathrm{mg}$ per oral, $\mathrm{N}$-Acetylcysteine $3 \times 200 \mathrm{mg}$ per oral, packed red cell $(\mathrm{PRC})$ transfusion of one bag per day, and TPM. On the third day of the treatment, electrocardiographic imaging indicated that the atrial fibrillation rhythm had a rapid ventricular response of 95-120 times per minute (Figure 5). As a consequence, the patient was given additional treatment with digoxin $0.25 \mathrm{mg}$ through intravenous infusion. Additionally, she was considered by the internist for haemodialysis (HD). This consideration was made based on the amount of BUN $138 \mathrm{mg} / \mathrm{dL}$ (normal range: 8 $23 \mathrm{mg} / \mathrm{dL}$ ) and serum creatinine $8.1 \mathrm{mg} / \mathrm{dL}$ (normal range: $0.6-1.3 \mathrm{mg} / \mathrm{dL}$ ) from the earlier laboratory results. The internist ultimately decided to administer HD using ultrafiltration $2000 \mathrm{ml}$ to this patient on the fourth day of treatment. The patient did not complain about chest pain on the next (fifth) day. The post-HD laboratory results showed that BUN reduced to $34 \mathrm{mg} / \mathrm{dL}$, serum creatinine to $1.05 \mathrm{mg} / \mathrm{dL}$ (eGFR $50 \mathrm{~mL} / \mathrm{min} / 1.73 \mathrm{~m}^{2}$ ). Afterwards, removal of the TPM was attempted on the ninth day (Figure 6). In this case, the patient was given additional therapy of salbutamol $4 \mathrm{mg}$ per oral three times a day. Later, the patient was discharged from the hospital on the fifteenth day. 


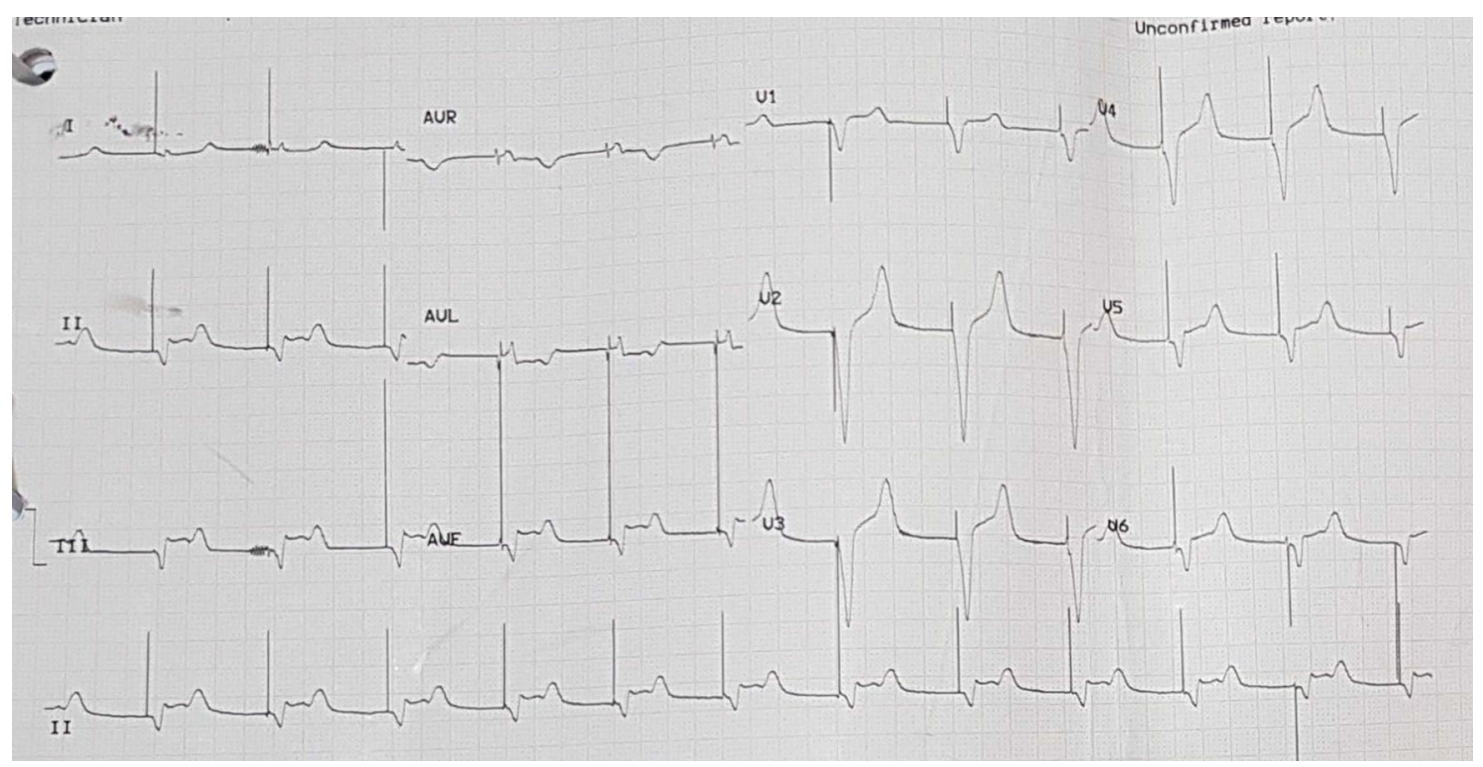

Figure 4. Electrocardiogram after pacemaker installation with rhythm.

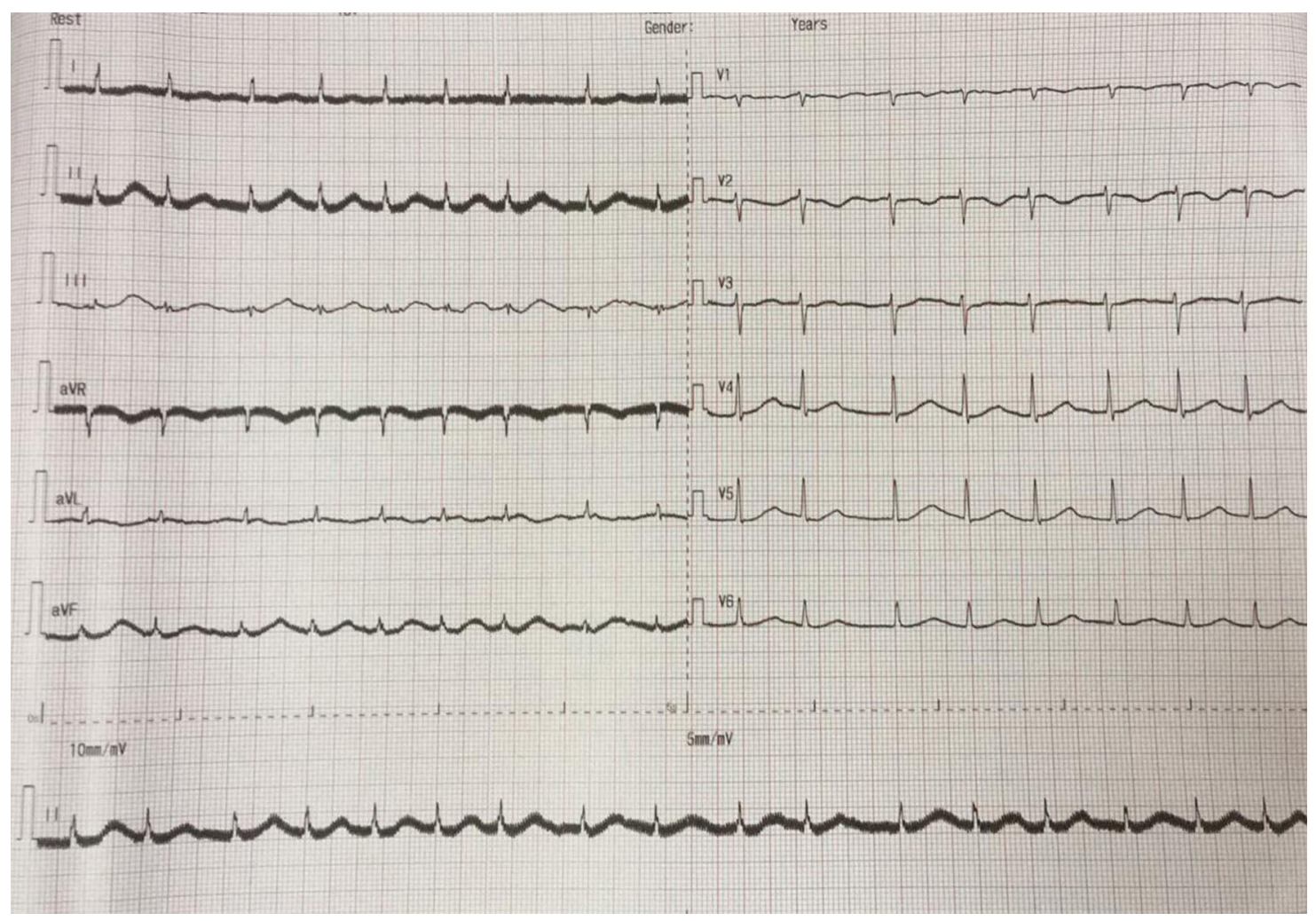

Figure 5. Electrocardiogram of patient in atrial fibrillation condition.

After three weeks of leaving the hospital, the patient was asked to undergo echocardiography. The results of this examination demonstrated that there was mild mitral regurgitation with normal cardiac chamber dimensions. The left ventricular systolic function seemed normal with ejection fraction by Teich being $68 \%$, as did the left ventricular diastolic function with E/A being 0.87 (Figure 7). On the other hand, the right ventricular systolic function appeared normal with tricuspid annular plane systolic excursion accounting for $1.8 \mathrm{~cm}$. 


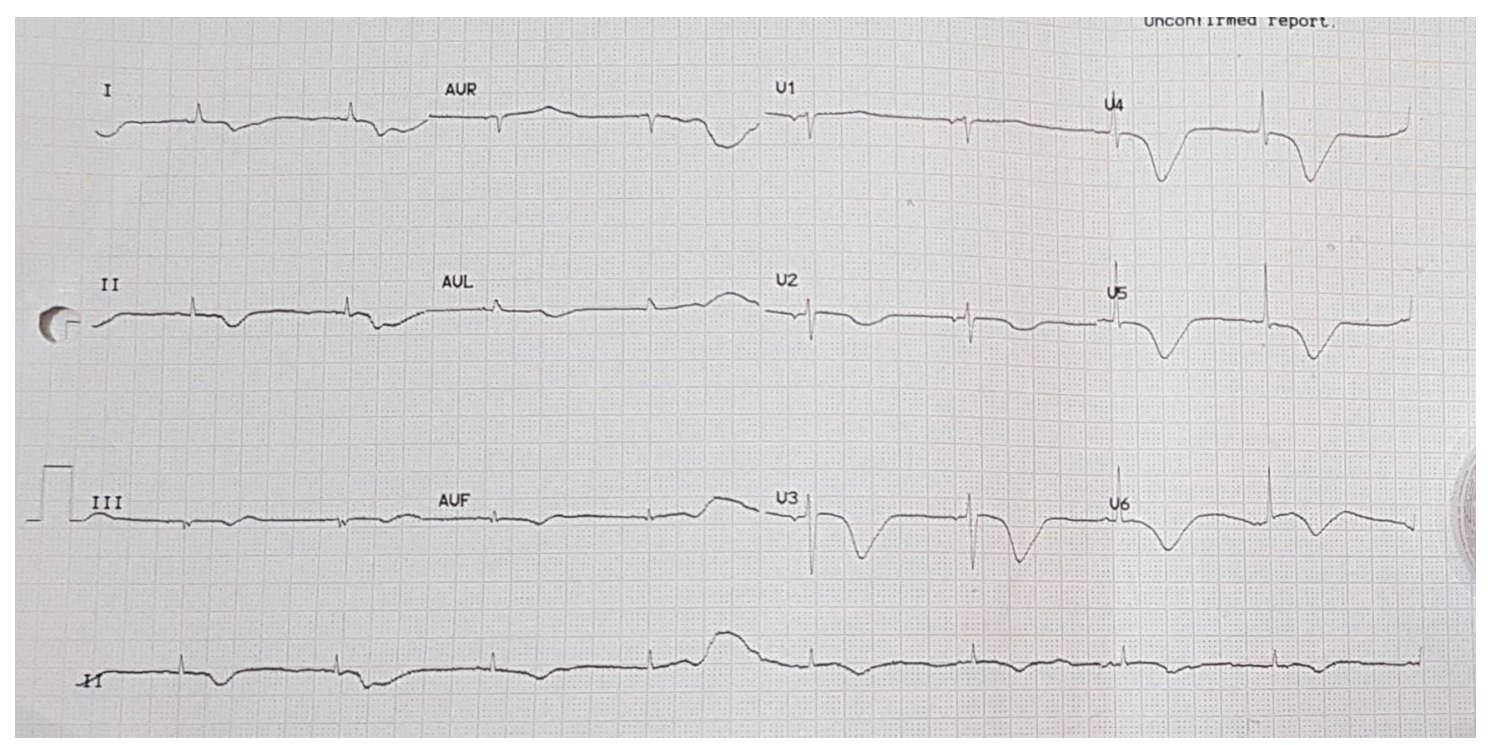

Figure 6. Electrocardiogram of patient with temporary pacemaker off and sinus bradycardia.

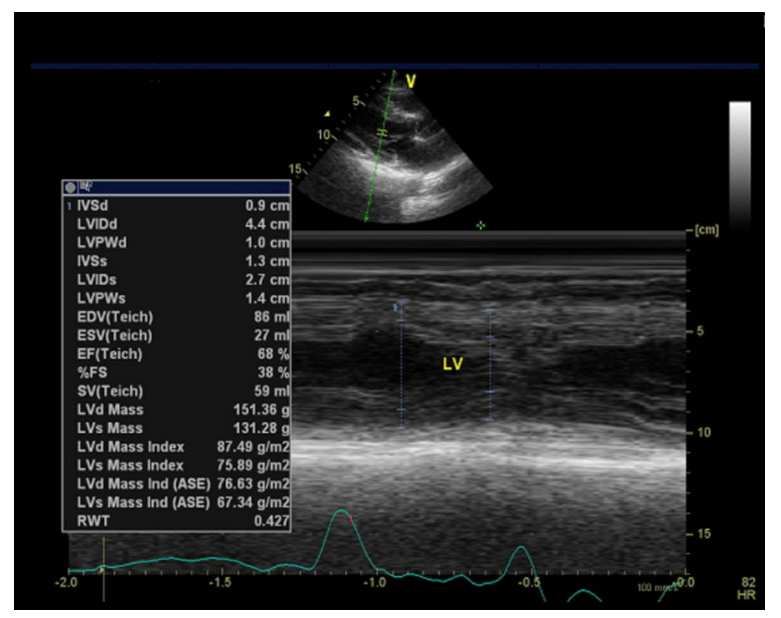

Figure 7. Echocardiography of third week after hospitalization.

\section{Discussion}

STEMI patients who have previously had kidney diseases or have recently suffered from kidney diseases as a result from STEMI have a worse prognosis. The renal insufficiency of patients with STEMI will increase the mortality and morbidity of cardiovascular diseases. ${ }^{4}$

Atherosclerotic coronary plaque can cause coronary arterial disease (CAD) in the general population, but for patients with $\mathrm{CKD}$, the pathophysiology of vascular diseases is different, due to a number of new risk factors, e.g., endothelium dysfunction, CKD-related mineral bone diseases, increased oxidative stress, and inflammation. In CKD, atherosclerosis often occurs in form of calcification of the lining of the blood vessels, which is regularly observed on peripheral vessels like the tibial and femoral arteries and on small epicardial blood vessels that contribute to microcirculation. There are many contributing factors to the incidence of chronic inflammation, such as increased oxidation and disrupted antioxidant system. These are particularly linked to hypoalbuminemia and malnutrition. Because of the deterioration of the renal function, the levels of pro-inflammatory cytokines and inflammatory mediators in the plasma will increase, thus leading to blood vessel calcification. ${ }^{4-6}$

The recent guidelines recommend that aspirin should be administered immediately after suspected acute coronary syndrome (ACS) and continued without a predetermined time, except if there is contraindication. ${ }^{7}$ Following that patients 
with renal insufficiency have an increased risk of bleeding, some doubt exists about the use of therapeutic antiplatelet therapy to such patients. According to the data collected, aspirin is safe and effective for ACS patients with CKD and recommended to be used in these patients to reduce mortality risk and vascular incidence. ${ }^{8}$

P2Y12 inhibitors are one of the common therapies given to patients with ACS. Various studies have shown the effectiveness of prasugrel and ticagrelor in the management of ACS. Although the risk of bleeding is relatively high, these drugs have a higher potential ratio of decreasing ischemic risk in CKD patients. The lack of alternative therapies related to the interaction of renal function allows clopidogrel to be considered as a treatment in patients with decreased renal function. For patients aged over 75 years old, clopidogrel can be administered at a loading dose of $75 \mathrm{mg}$ and followed with a dose of $75 \mathrm{mg} /$ day for maintenance. ${ }^{9}$

A number of studies suggested that statins should be used to treat ACS in order to reduce death risk or vascular incidence. American Heart Association guidelines recommend that statins should be given without seeing the initial levels of lowdensity lipoprotein in ACS patients without any contraindications. ${ }^{8}$

The use of lipid-lowering therapy, especially with statins, in patients with CKD remains a controversy to date. The potential of a statin-based treatment to decrease the number of vascular events will become much smaller due to a decrease in eGFR. The KDIGO guidelines propose that statins should be used in CKD patients over 50 years old, but not in dialysis patients. This recommendation is mainly based on two studies, namely 4D (Deutsche Diabetes Dialyse Studie) and AURORA (Rosuvastatin use evaluation). Nonetheless, statins still function as the foundation of the lipid management of CKD patients with CAD. In other words, giving statins to ACS patients with CKD is highly recommended. ${ }^{4,8,10}$

Whether patients with the symptoms of CKD and/or end-stage renal disease should be treated with medical therapy or revascularization through either PCI or coronary artery bypass grafting is still debatable. In many cases, STEMI patients with CKD undergo the same invasive treatment as STEMI patients with no CKD. This is adherent to the fact that no specific clinical trial has been conducted of patients with CKD. Although the research appears to be more supportive of initial invasive treatment than of initial conservative treatment, there is no survival benefit from early intervention in CKD patients within a range of Grade 3 a to Grade $5\left(<60 \mathrm{ml} / \mathrm{min} / 1.73 \mathrm{~m}^{2}\right)$ in non-ST-segment-elevation randomized controlled trials of myocardial infarction. ${ }^{10}$

There is no contraindication observed in the thrombolytic therapy in this case. Nevertheless, when the worsened CKD and the in-hospital mortality rate are taken into account as a result from myocardial infarction, primary PCI should be chosen. $^{10-12}$

Total AV block is common in inferior STEMI and is often transient only and sometimes it can return within 5 to 7 days. Treatment with a temporary pacemaker and PCI is needed to deal with this problem. Meanwhile, the management of STEMI in elderly patients is generally the same as in adult patients. In a retrospective study of 57,000 patients with the acute coronary syndrome ( $>75$ years old) who received recommended therapy, the in-hospital mortality rate was lower than that of those who did not. ${ }^{13}$

This case presents a new successfully reperfusion therapy in octogenarian patient with kidney disease. The limitation of this case is that we did not perform further diagnostic tests to find out the underlying disease that had caused the kidney disease.

\section{Conclusions}

The prognosis of patients with decreased renal function and acute myocardial infarction is relatively poor, considering that these two conditions worsen each other. An increased rate of major adverse cardiovascular events, heart failure, and chest pain are seen in line with decreased eGFR rate. In this study, we reported the treatment of a patient of 80 years old suffering from acute myocardial infarction with ACKD and TAVB. The patient, with inferior STEMI, complicated by total AV block, was treated with coronary angioplasty and hemodialysis and those were performed successfully. The complaint of ischemic chest pain was resolved, and renal function was improved. In this regard, serum creatinine decreased from $8 \mathrm{mg} / \mathrm{dL}$ to $1.05 \mathrm{mg} / \mathrm{dL}$, with eGFR being $50 \mathrm{~mL} / \mathrm{min} / 1.73 \mathrm{~m}^{2}$.

\section{Data availability}

All data underlying the results are available as part of the article and no additional source data are required.

\section{Consent}

Written informed consent for publication of their clinical details and/or clinical images was obtained from the patient. 
1. Sinkovič A, Masnik K, Mihevc M: Predictors of acute kidney injury (AKI) in high-risk st-elevation myocardial infarction (STEMI) patients: A single-center retrospective observational study. Bosn J Basic Med Sci. 2019.

PubMed Abstract | Publisher Full Text | Free Full Text

2. Madhavan MV, Gersh BJ, Alexander KP, et al.: Coronary artery disease in patients $\geq \mathbf{8 0}$ years of age. / Am Coll Cardiol. 2018. PubMed Abstract | Publisher Full Text

3. Fox KAA, Clayton TC, Damman P, et al.: Long-term outcome of a routine versus selective invasive strategy in patients with non-ST-segment elevation acute coronary syndrome. A meta-analysis of individual patient data. J Am Coll Cardiol. 2010. PubMed Abstract | Publisher Full Text

4. Lakkas LS, Gkirdis I: Management of patients with coronary artery disease and chronic kidney disease. Contin Cardiol Educ. 2017

Publisher Full Text

5. Mallappallil M, Friedman EA, Delano BG, et al.: Chronic kidney disease in the elderly: Evaluation and management. Clin Pract. 2014

PubMed Abstract | Publisher Full Text | Free Full Text

6. Moore PK, Hsu RK, Liu KD: Management of acute kidney injury: Core curriculum 2018. Am J Kidney Dis. 2018. PubMed Abstract | Publisher Full Text

7. Ibanez B, James S, Agewall S, et al.: ESC Guidelines for the management of acute myocardial infarction in patients presenting with ST-segment elevation. Eur Heart J. 2017: 2018. PubMed Abstract | Publisher Full Text

8. Washam JB, Herzog CA, Beitelshees AL, et al.: Pharmacotherapy in chronic kidney disease patients presenting with acute coronary syndrome: A scientific statement from the American Heart Association. Circulation. 2015.

PubMed Abstract | Publisher Full Text

9. Bonello L, Angiolillo DJ, Aradi D, et al.: P2Y12-ADP receptor blockade in chronic kidney disease patients with acute coronary syndromes review of the current evidence. Circulation. 2018. Publisher Full Text

10. Sarnak MJ, Amann K, Bangalore S, et al.: Chronic kidney disease and coronary artery disease: JACC state-of-the-art review. J Am Coll Cardiol. 2019. PubMed Abstract | Publisher Full Text

11. Keriakos R: Kidney disease. In: Antenatal Disorders for the MRCOG and Beyond. 2016. Publisher Full Text

12. Appleby CE, IvanovJ, Lavi S, et al.: The adverse long-term impact of renal impairment in patients undergoing percutaneous coronary intervention in the drug-eluting Stent Era. Circ Cardiovasc Interv. 2009. PubMed Abstract | Publisher Full Text

13. Alexander KP, Roe MT, Chen AY, et al.: Evolution in cardiovascular care for elderly patients with non-ST-segment elevation acute coronary syndromes: Results from the CRUSADE National Quality Improvement Initiative. J Am Coll Cardiol. 2005; 46: 1479. 


\section{Open Peer Review}

\section{Current Peer Review Status:}

\section{Version 2}

Reviewer Report 16 February 2022

https://doi.org/10.5256/f1000research.120591.r123006

(c) 2022 Firoze $\mathbf{M}$. This is an open access peer review report distributed under the terms of the Creative Commons Attribution License, which permits unrestricted use, distribution, and reproduction in any medium, provided the original work is properly cited.

\section{Mohammad Ullah Firoze}

Department of Cardiology, Dhaka Medical College, Dhaka, Bangladesh

Thank you. Authors have tried to answer most of the questions and had made some corrections. I think this can be indexed as a case report.

Competing Interests: No competing interests were disclosed.

Reviewer Expertise: My area of interest is cardiovascular medicine.

I confirm that I have read this submission and believe that I have an appropriate level of expertise to confirm that it is of an acceptable scientific standard.

\section{Version 1}

Reviewer Report 11 November 2021

https://doi.org/10.5256/f1000research.55068.r89511

(C) 2021 Ojji D. This is an open access peer review report distributed under the terms of the Creative Commons Attribution License, which permits unrestricted use, distribution, and reproduction in any medium, provided the original work is properly cited.

Dike B Ojji

${ }^{1}$ Department of Medicine, Faculty of Clinical Sciences, University of Abuja, Abuja, Nigeria

2 Department of Medicine, Faculty of Clinical Sciences, University of Abuja, Abuja, Nigeria

In this case report the authors report a case of an octogenarian patient suffering from STEMI with ACKD and total atrioventricular block (TAVB), who underwent insertion of a temporary pacemaker 
and primary PCI.

Patient also had improved renal function after dialysis by decreasing the amount of serum creatinine from $8.1 \mathrm{mg} / \mathrm{dL}$ at admission to $1.05 \mathrm{mg} / \mathrm{dL}$ after primary PCI and dialysis.

This is an interesting, but the authors have to address some issues to make it more interesting: Majorly, the discussion is too broad and was not directly in reference to the case study. Since this is a case report the the findings in this patients should be cited throughout the discussion section.

On the minor side:

I think the statement in the case report session: 'In this regard, the patient had a history of hypertension' is is not clear and need to be rephrased.

History hypertension was mentioned but BP was $116 / 53 \mathrm{mmHg}$. Is patient on any anti-hypertensives.

What is meant by the statement: 'we provided this patient with a diagnosis of inferior STEMI with total AV block and ACKD. What is meant by provided'. I think this has to be rephrased.

Is the background of the case's history and progression described in sufficient detail? Yes

Are enough details provided of any physical examination and diagnostic tests, treatment given and outcomes?

Yes

Is sufficient discussion included of the importance of the findings and their relevance to future understanding of disease processes, diagnosis or treatment?

Yes

Is the case presented with sufficient detail to be useful for other practitioners? Yes

Competing Interests: No competing interests were disclosed.

Reviewer Expertise: Preventive Cardiology; Hypertension; Hypertensive Heart Failure; Echocardiography

I confirm that I have read this submission and believe that I have an appropriate level of expertise to state that I do not consider it to be of an acceptable scientific standard, for reasons outlined above. 


\section{Ni Putu Anggun Laksmi}

In this case report the authors report a case of an octogenarian patient suffering from STEMI with ACKD and total atrioventricular block (TAVB), who underwent insertion of a temporary pacemaker and primary PCI.Patient also had improved renal function after dialysis by decreasing the amount of serum creatinine from $8.1 \mathrm{mg} / \mathrm{dL}$ at admission to $1.05 \mathrm{mg} / \mathrm{dL}$ after primary $P C I$ and dialysis. This is an interesting, but the authors have to address some issues to make it more interesting. Majorly, the discussion is too broad and was not directly in reference to the case study. Since this is a case report the findings in this patient should be cited throughout the discussion section.

Response: Thank you very much for the advice. We had already cited the findings in this patient in the $10^{\text {th }}$ paragraph of discussion section

On the minor side:I think the statement in the case report session: "In this regard, the patient had a history of hypertension" is not clear and need to be rephrased.

Response: Thank you for the advice, we have rephrased it.

History hypertension was mentioned but BP was $116 / 53 \mathrm{mmHg}$. Is patient on any antihypertensives.

Response: The patient said that she had a history of hypertension and had previously taken amlodipine $5 \mathrm{mg}$, but her blood pressure had been normal for the past months, and she had stopped taking it. Once again, thank you for the advice. We really appreciate it.

What is meant by the statement: "We provided this patient with a diagnosis of inferior STEMI with total AV block and ACKD. What is meant by provided". I think this has to be rephrased.

Response: Thank you for the advice, we have rephrased it.

Competing Interests: No competing interests were disclosed.

Reviewer Report 26 July 2021

https://doi.org/10.5256/f1000research.55068.r89510

(c) 2021 Firoze M. This is an open access peer review report distributed under the terms of the Creative Commons Attribution License, which permits unrestricted use, distribution, and reproduction in any medium, provided the original work is properly cited.

\section{Mohammad Ullah Firoze}

${ }^{1}$ Department of Cardiology, Dhaka Medical College, Dhaka, Bangladesh

2 Department of Cardiology, Dhaka Medical College, Dhaka, Bangladesh

This is a nice case report to focus on the issue of primary PCI in octogenarians and in patients with 
renal failure. It's not a new method or rare event, but it will draw attention of the readers to this issue. But it needs some correction and clarifications:

1. Figure 1 is showing sinus bradycardia not CHB. It should be corrected.

2. Total occlusion is better seen in first figure of Fig-3. So, it should be the first figure of Fig 2 . And the first figure of Fig 2 should be the first figure of Fig 3. These two figures should be swapped.

3. N-Acetylcysteine was given in the form fluimucyl. It should be mentioned as generic name.

4. Why was daily packed red cell transfusion given?

5. Was the addition of anticoagulation considered during AF?

6. Why was digoxin used in ACS with AF with renal failure instead of beta blocker or amiodarone?

7. The ECG after removal of TPM there was sinus bradycardia with a rate of $52 / \mathrm{min}$ and QTC of $559 \mathrm{msec}$ and t wave inversions. What was the rationale for using salbutamol? What was the possible cause of prolong QTc with T wave inversion? Was there any electrolyte imbalance? What was the rhythm and rate during discharge?

8. What was the baseline echo during admission? What was the possible cause of moderate MR at three weeks? What was the renal function and ECG status at three weeks after hospital discharge?

9. Discussion- PPCI in octogenarians and management of $\mathrm{CHB}$ in ACS could be discussed.

10. CIN could be discussed.

11. Justification of hemodialysis should also be discussed. Whether it was done only because of high creatinine level? And what was the creatinine level on the fourth day before starting haemodialysis? Haemodialysis for contrast clearing is not recommended. What was the creatinine level on the day of discharge?

12. This is not a new reperfusion therapy- as mentioned in discussion.

13. Conclusion- It could be more concise. $4^{\text {th }} \& 5^{\text {th }}$ sentence could be single sentence. $6^{\text {th }} \& 7^{\text {th }}$ sentence are not necessary. Rather a recommendation from the authors could be added.

14. Either CHB or TAVB - anyone of them should be used in the text.

Is the background of the case's history and progression described in sufficient detail? Partly

Are enough details provided of any physical examination and diagnostic tests, treatment given and outcomes? 
Partly

Is sufficient discussion included of the importance of the findings and their relevance to future understanding of disease processes, diagnosis or treatment?

No

Is the case presented with sufficient detail to be useful for other practitioners?

Partly

Competing Interests: No competing interests were disclosed.

Reviewer Expertise: My area of interest is cardiovascular medicine.

I confirm that I have read this submission and believe that I have an appropriate level of expertise to confirm that it is of an acceptable scientific standard, however I have significant reservations, as outlined above.

Author Response 23 Jan 2022

\section{Andrianto Andrianto}

1. Figure 1 is showing sinus bradycardia not CHB. It should be corrected.

Answer: Thank you very much for the correction. We have attached the ECG result during inferior STEMI with TAVB in this patient.

2. Total occlusion is better seen in first figure of Fig-3. So, it should be the first figure of Fig

2. And the first figure of Fig 2 should be the first figure of Fig 3. These two figures should be swapped.

Answer: Thank you very much. We will revise it.

3. N-Acetylcysteine was given in the form fluimucyl. It should be mentioned as generic name.

Answer: Thank you very much. We have amended it.

4. Why was daily packed red cell transfusion given?

Answer: Packed red cell transfusion was administered due to anemia ( $\mathrm{Hb} 8.6 \mathrm{~g} / \mathrm{dL}$ ).

5. Was the addition of anticoagulation considered during AF?

Answer: The patient had paroxysmal atrial fibrillation, and, at that time, we did not consider adding an anticoagulant, but we considered the high risk of bleeding in the elderly.

6. Why was digoxin used in ACS with AF with renal failure instead of beta blocker or amiodarone?

Answer: Because there were no intravenous beta-blockers in the hospital at that time. Thus, it was digoxin that could be considered. Patients with stage 5 chronic kidney disease (glomerular filtration rate [GFR] $<15 \mathrm{~mL} /$ minute), or for those on hemodialysis, alternative agents (e.g., beta-blockers or nondihydropyridine calcium channel blockers) may be 
preferred for heart rate control; however, it is recommended to reduce the loading dose of 3 to $5 \mathrm{mcg} / \mathrm{kg}$ ( 0.25 to $0.375 \mathrm{mg}$ ) should digoxin be used.

7. The ECG after removal of TPM there was sinus bradycardia with a rate of $52 / \mathrm{min}$ and QTC of $559 \mathrm{msec}$ and $\mathrm{t}$ wave inversions. What was the rationale for using salbutamol? What was the possible cause of prolong QTc with T wave inversion? Was there any electrolyte imbalance? What was the rhythm and rate during discharge?

Answer: Well, thank you very much. As a beta-agonist, Salbutamol is expected to have a positive chronotropic effect in this patient. Yes, the patient had an electrolyte imbalance, namely hypokalemia of $2.8 \mathrm{meq} / \mathrm{l}$, which had been corrected. On discharge, the patient had asymptomatic sinus bradycardia at $55 \mathrm{bpm}$.

8. What was the baseline echo during admission? What was the possible cause of moderate MR at three weeks? What was the renal function and ECG status at three weeks after hospital discharge?

Answer: We apologize for the mistake. There was mild mitral regurgitation on the patient's echocardiography, instead of moderate MR. The renal function was improved after hospital discharge. BUN was $34 \mathrm{mg} / \mathrm{dL}$ (normal range: $8-23 \mathrm{mg} / \mathrm{dL}$ ), and serum creatinine was 1.05 $\mathrm{mg} / \mathrm{dL}$ (normal range: $0.6-1.3 \mathrm{mg} / \mathrm{dL}$ ).

9. Discussion- PPCI in octogenarians and management of CHB in ACS could be discussed. Answer: Thank you very much. We will include your suggestions in the revised article.

10. CIN could be discussed.

Answer: Thank you very much for your advice.

11. Justification of hemodialysis should also be discussed. Whether it was done only because of high creatinine level? And what was the creatinine level on the fourth day before starting haemodialysis? Haemodialysis for contrast clearing is not recommended. What was the creatinine level on the day of discharge?

Answer: Yes, it was done because of the high level of creatinine $(8.1 \mathrm{mg} / \mathrm{dL})$ and BUN (138 $\mathrm{mg} / \mathrm{dL}$ ). The creatinine level on the fourth day before starting hemodialysis was $5.8 \mathrm{mg} / \mathrm{dl}$ and BUN $109 \mathrm{mg} / \mathrm{dl}$. On discharge, BUN was $34 \mathrm{mg} / \mathrm{dL}$, and serum creatinine was 1.05 $\mathrm{mg} / \mathrm{dL}$.

12. This is not a new reperfusion therapy- as mentioned in discussion. Answer: We are very thankyou for the advise.

13. Conclusion- It could be more concise. 4 th \& 5th sentence could be single sentence. 6 th \& 7 th sentence are not necessary. Rather a recommendation from the authors could be added.

Answer: Thank you very much for your advice.

14. Either CHB or TAVB - anyone of them should be used in the text.

Answer: Thank you. We use the term Total AV block. 
Competing Interests: We have no competing interests in this article

The benefits of publishing with F1000Research:

- Your article is published within days, with no editorial bias

- You can publish traditional articles, null/negative results, case reports, data notes and more

- The peer review process is transparent and collaborative

- Your article is indexed in PubMed after passing peer review

- Dedicated customer support at every stage

For pre-submission enquiries, contact research@f1000.com 